IRA-International Journal of Technology \& Engineering ISSN 2455-4480

Proceedings of the

International Conference on Science \& Engineering for Sustainable Development (2017)

Pg. no. 19-33

Published by: Institute of Research Advances https://research-advances.org/index.php/IRAJTE

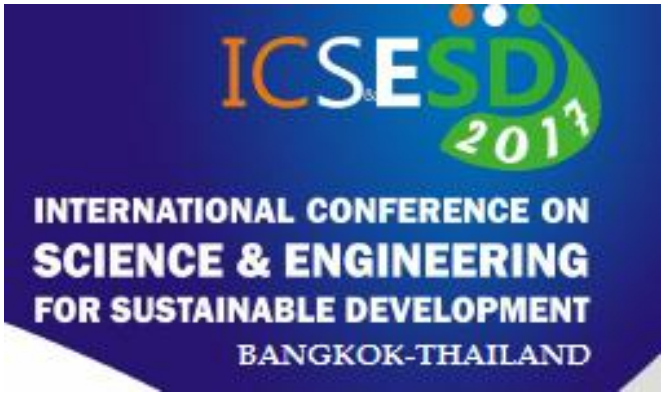

\title{
Application of Solar Thermal Energy for Medium Temperature Heating in Automobile Industry
}

\author{
Anagha Pathak ${ }^{1}$, Kiran Deshpande ${ }^{2}$ and Sandesh Jadkar ${ }^{3}$ \\ ${ }^{1,2,3}$ School of Energy Studies, Savitribai Phule Pune University, Pune 411 007, India. \\ E-mail: drpathakam@gmail.com Phone (office): +91 202569 5201, Mobile (+91 \\ 9823021066)
}

Type of Review: Originality Check \& Peer Review under the responsibility of the Scientific Committee of the Conference and The Institution of Engineers (India). DOI: http://dx.doi.org/10.21013/jte.ICSESD201703

\section{How to cite this paper:}

Pathak, A., Deshpande, K., Jadkar, S. (2017). Application of Solar Thermal Energy for Medium Temperature Heating in Automobile Industry. Proceedings of the International Conference on Science \& Engineering for Sustainable Development (2017), 19-33. doi: http://dx.doi.org/10.21013/ite.ICSESD201703

(C) International Conference on Science \& Engineering for Sustainable Development\& The Institution of Engineers (India).

\section{(cc) EY-NC}

This work is licensed under a Creative Commons Attribution-Non Commercial 4.0 International License subject to proper citation to the publication source of the work.

Disclaimer: The conference papers as published by the Institute of Research Advances (IRA) are the views and opinions of their respective authors and are not the views or opinions of the IRA. The IRA disclaims of any harm or loss caused due to the published content to any party. 


\section{ABSTRACT}

There is a huge potential to deploy solar thermal energy in process heat applications in industrial sectors. Around $50 \%$ of industrial heat demand is less than $250^{\circ} \mathrm{C}$ which can be addressed through solar energy. The heat energy requirement of industries like automobile, auto ancillary, metal processing, food and beverages, textile, chemical, pharmaceuticals, paper and pulp, hospitality, and educational institutes etc. can be partially met with solar hybridization based solutions. The automobile industry is one of the large consumers of fossil fuel energy in the world. The automobile industry is major economic growth driver of India and has its $60 \%$ fuel dependence on electricity and remaining on oil based products. With abundant area available on roof top, and need for medium temperature operation makes this sector most suitable for substitution of fossil fuel with renewable solar energy. Auto sector has requirement of heat in the temperature range of $80-140{ }^{\circ} \mathrm{C}$ or steam up to 2 bar pressure for various processes like component washing, degreasing, drying, boiler feed water preheating, LPG vaporization and cooling. This paper discusses use of solar energy through seamless integration with existing heat source for a few processes involved in automobile industries. Integration of the concentrated solar thermal technology (CST) with the existing heating system is discussed with a case study for commonly used processes in auto industry such as component washing, degreasing and phosphating. The present study is undertaken in a leading automobile plant in India. Component cleaning, degreasing and phosphating are important processes which are carried out in multiple water tanks of varying temperatures. Temperatures of tanks are maintained by electrical heaters which consumes substantial amount of electricity. Non-imaging solar collectors, also known as compound parabolic concentrators (CPC) are used for generation of hot water at required process temperature. The CPC are non-tracking collectors which concentrate diffuse and beam radiation to generate hot water at required temperature. The solar heat generation plant consists of CPC collectors, circulation pump and water storage tank with controls. The heat gained by solar collectors is transferred through the storage tank to the process. An electric heater is switched on automatically when the desired temperature cannot be reached during lower radiation level or during non-sunny hours/days. This solar heating system is designed with CPC collectors that generate process heating water as high as $90^{\circ} \mathrm{C}$. It also seamlessly integrates with the existing system without compromising on its reliability, while reducing electricity consumption drastically. The system is commissioned in April, 2013 and since then it has saved 1,75,000 units of electricity/year and in turn $164 \mathrm{MT}$ of emission of $\mathrm{CO}_{2}$ annually.

Keywords: Compound Parabolic Concentrators, Industrial Process heat, Solar Thermal

\section{Introduction}

Globally, industrial process heat accounts for more than two-thirds of total energy consumption in industry, and half of this process heat demand is low- to medium-temperatures $\left(<400{ }^{0} \mathrm{C}\right)$. Prime application areas for solar thermal systems are in the industries like automobile, auto ancillary, metal processing, food and beverages, textile, chemical, pharmaceuticals, paper and pulp, hospitality, and educational institutes etc. where about $60 \%$ of the heating needs can be met by temperatures below 250 ${ }^{0} \mathrm{C}$. Solar thermal energy can fulfill a substantial amount of heat demand in industrial processes within any given country and irrespective of the geographical location. Considering need for conservation of fossil fuel and reducing carbon emission, it is necessary to shift to renewable energy like solar, biomass etc. While biomass energy will have to be balanced with food requirements, use of solar energy which is 
available right in the premises of industry i.e. in open areas or on roof tops can be harvested efficiently. In many industries, the requirement of heat energy can be met by solar at least during day time. This paper also discusses one case in Automobile and Components industry which has huge potential for shifting to solar energy [1-4].

\section{AUTOMOBILE SECTOR}

The automobile industry is one of the large consumers of fossil fuel energy in the world. The Auto industry is major economic growth driver of India and has $60 \%$ fuel dependence on electricity and balance on petroleum products [5]. With abundant area available on roof top, and need for medium temperature operation makes this sector most suitable for substitution of fossil fuel with renewable solar energy. Auto sector has requirement of heat in the temperature range of $80-140{ }^{\circ} \mathrm{C}$ or steam up to 2 bar pressure for various processes like component washing, degreasing, drying, boiler feed water preheating, LPG vaporization and cooling. Table 1 specifies various applications in the auto sector along with the pressure and temperature requirements $[7,1-4]$.

Table 1: Temperature requirement for various processes in automobile industry

\begin{tabular}{lll}
\hline Application & Utilization & Pressure/Temperature \\
\hline Component washing & Engine assembly & Hot Water at $60-90{ }^{\circ} \mathrm{C}$ \\
Component washing & Electro Plating & Hot water at $60-90{ }^{\circ} \mathrm{C}$ \\
Degreasing & Paint shop/Phosphating & Hot water at $60-90{ }^{\circ} \mathrm{C}$ \\
Drying & Paint booth & Hot air at $120{ }^{\circ} \mathrm{C}$ \\
LPG Vaporizer & In various machines & Hot water at $70-80{ }^{0} \mathrm{C}$ \\
Steam cooking & Canteen & $1-2$ bar \\
Washing & Various processes & $60-80{ }^{\circ} \mathrm{C}$ \\
Solar cooling & Paint shop & $120-140{ }^{\circ} \mathrm{C}$ \\
Boiler feed water & At boiler & Hot water at $90{ }^{\circ} \mathrm{C}$ \\
\hline
\end{tabular}

\section{CONCENTRATING SOLAR THERMAL (CST) TECHNOLOGY}

The concentrating solar thermal (CST) technologies can generate hot water or steam at various temperatures and pressure ranges depending on the degree of concentration of solar energy. The CST is a device which can concentrate solar radiation many times using mirrors/lenses, resulting in temperatures in the range of 100 to $450{ }^{\circ} \mathrm{C}$ or even more. These devices need tracking so as to focus sun rays on a receiver all the time. Solar energy is received in direct and diffused form and CST harvests the direct normal radiation. The only exception is non-imaging concentrator, also called as compound parabolic concentrator (CPC) which uses direct as well as diffuse radiation. The CST systems are useful for medium and high temperatures required for various applications in industries, commercial establishments 
and institutions. Various concentrating solar thermal technologies are available and can be deployed depending on temperature range required for the process $[6,1-4]$, some of them are mentioned below in figure 1.

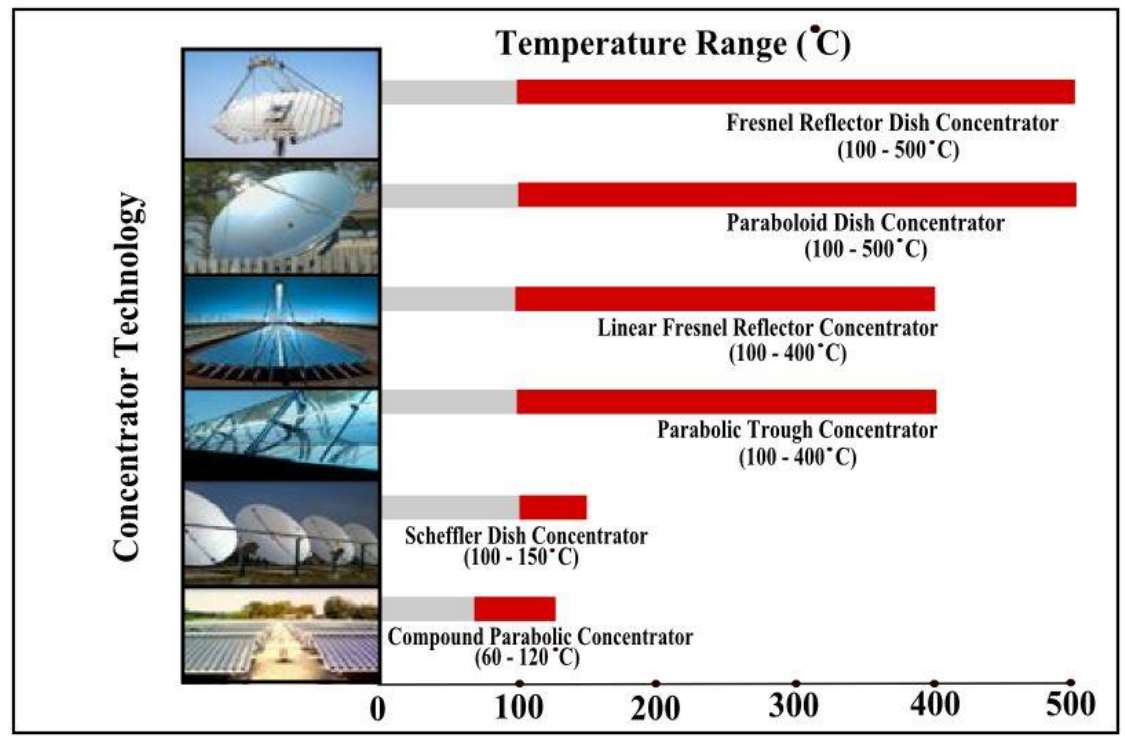

Figure 1: Temperature ranges of different CST technologies

\section{SOLAR TECHNOLOGY INTEGRATION}

The solar collector's heat generation depends on the input solar radiations which vary widely from morning to evening and from winter to summer. However, industrial process needs on demand stable source of heat energy and variation is not acceptable. The challenge of ensuring consistent supply of heat to plant while using all the solar energy available on collector area can be addressed by integration of solar thermal technology with existing heating source which can be fossil fuel, electricity or biomass. Such integration scheme utilizes full solar energy potential while supporting conventional fuel is used during low solar energy period, nights and cloudy days. The integration scheme with the existing heating system to meet the heat and temperature requirement is suggested for few processes in automobile industries such as LPG vaporization, furnace oil heating, seven tank dip zinc phosphating processes.

\section{LPG Vaporization Using Solar Thermal Energy}

Liquefied Petroleum Gas, also called as LPG, GPL, LP Gas, or auto gas, is a flammable mixture of hydrocarbon gases used as a fuel in heating appliances and vehicles. LPG is stored in pressurized containers or tanks in liquid form. As LPG vapor is being used as a fuel for connected equipments like burners, heaters, etc., liquid LPG must vaporize to change its state from liquid to gas, before being used. This is done by LPG vaporizer as per the requirement [7]. 


\section{1(a): Present System}

For vaporization of LPG, following method is commonly used. A vaporizer is designed to receive the liquid LPG and raise its temperature to heat the liquid well above the boiling point at the delivery pressure. LPG is vaporized by heating indirectly, using hot water of temperature around $80-85{ }^{\circ} \mathrm{C}$, either in closed loop or hot water bath system. The water is heated using electric heaters. The figure 2 shows a typical hot water bath system.

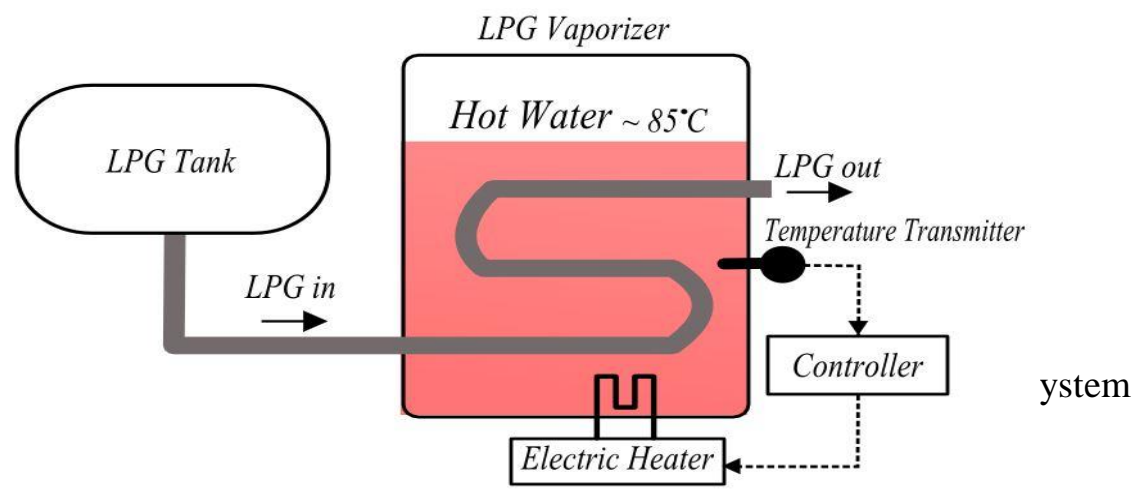

Some characteristics of LPG vaporizer system are listed below,

$\begin{array}{ll}\text { Electrical heating capacity } & : 12 \mathrm{~kW} \text { (Minimum) and } 132 \mathrm{~kW} \text { (Maximum) } \\ \text { Temperature required } & : 85{ }^{\circ} \mathrm{C} \\ \text { Application of LPG in plant } & : \text { Boiler, Furnaces, Chillers, Cooking etc. } \\ \text { Existing mode of heating } & : \text { Electrical } \\ \text { Operation } & : \text { Batch and Continuous process }\end{array}$

\section{1(b): Solar Integration with LPG Vaporizer System}

Solar system is integrated with the present system for LPG vaporization. The required heat of vaporization is supplied by solar concentrator, reducing equivalent electrical consumption. The figure 3 below shows the integration of solar system with a typical electrical heating system commonly used in automobile industries. Water is circulated through solar field in closed loop which quickly reaches the desired temperature required for vaporization i.e. $\sim 85^{\circ} \mathrm{C}$. Once the desired temperature of solar system is reached, water is passed through the LPG vaporizer to heat the LPG in liquid phase. The heat will be transferred to the liquid LPG to change it to vapor form. The outlet water of lower temperature will be circulated through the solar field again. In some cases, the hot water/ fluid is stored in a separate tank where desired temperature is maintained and given to LPG vaporizer. During non sunny hours, the solar system temperature drops due to non availability of solar energy and the system automatically starts electrical heaters using temperature controller feedback loop.

The type of solar concentrating system depends on the specific site conditions and space availability. 


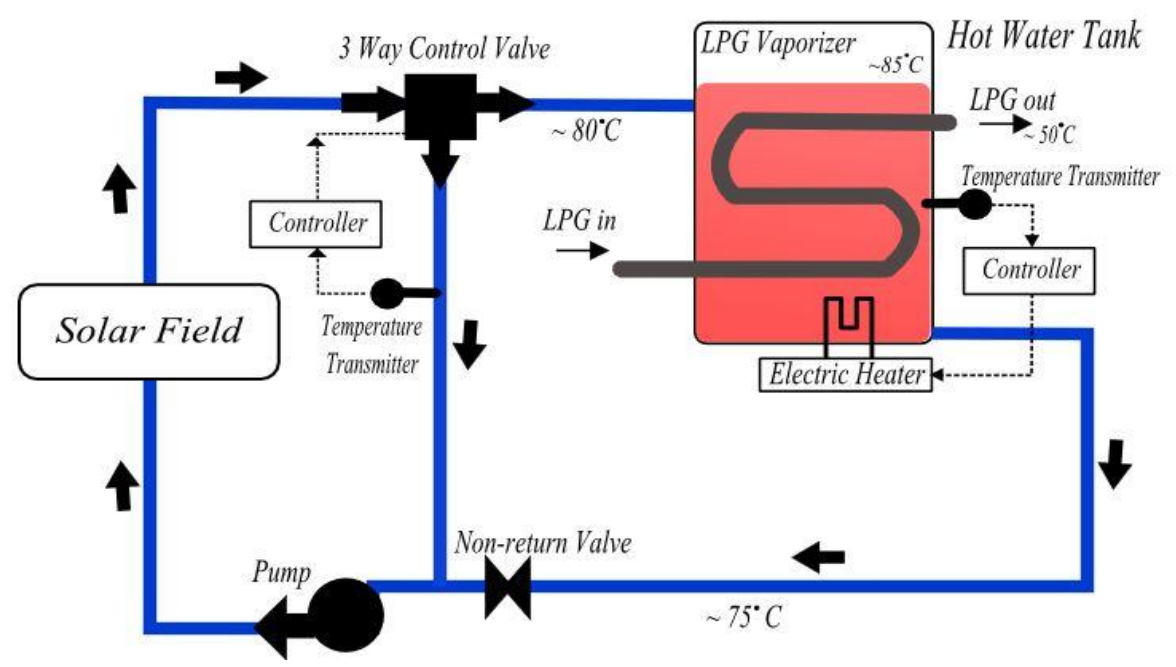

Figure 3: Integration of solar system with existing LPG vaporizer

\section{Furnace Oil Heating by Solar Thermal Energy}

Furnace Oil (FO) or heavy oil is a liquid fuel which is widely used in the industry for all sizes of steam boilers, furnaces, ovens, captive power plants etc. It is very viscous fuel at ambient conditions and requires pre-heating to reduce viscosity and enable it to be atomized at the burner tips. Atomization is required to ensure proper handling and combustion of the fuel. The need is therefore to heat up the FO when stored in tanks and before firing in a burner. Typical oil pre-heating temperature before firing is in the range of $100-130{ }^{\circ} \mathrm{C}$. This is ideal application of solar energy where steam or electricity used for preheating can be substituted with solar energy [8].

\section{2(a): Typical Furnace Oil Preheating System}

For FO heating, two types of systems are most commonly used. These are,

1) Electrical heating: Electrical heating is provided to the coil heaters in the form of a bank and installed at the FO tank and also near the burner. Electrical heating meets the entire heat demand of FO heating. The electrical heating is controlled by using temperature feedback.

2) Steam heating: Steam coils are used and heating is provided to heat up the FO before entering the burner or other application. Electrical heating is used only during start up. Thereafter steam is provided for FO pre-heating through a heat exchanger. The required temperature is maintained by controlling steam valve. Thus, FO temperature required at the burner is in the range of $100{ }^{\circ} \mathrm{C}$ to $130{ }^{\circ} \mathrm{C}$ depending on the fuel quality and is maintained by using electricity or steam. In a typical system, a FO pump is used to pump fuel from FO tank to FO heater and then to the burner. The FO heater controller ensures that FO is provided to the burner at the required temperature. 
Furnace oil heating system details of one such system in automobile industry are listed below,

Electrical heating Capacity

Temperature required

Application of FO in plant

Existing mode of heating

Operation
: $12 \mathrm{~kW}$ (Minimum) and $132 \mathrm{~kW}$ (Maximum)

$: 130{ }^{\circ} \mathrm{C}$

: Boiler, Furnaces etc.

: Electrical and steam

: Continuous process

2(b): Solar Integration with Furnace Oil Heating System

A solar concentrator system can be installed to generate low pressure steam for meeting the heat load of FO heating. Solar energy can be utilized for 6-7 hours per day for about 270 days in a year in India. The conventional system of steam or electrical heater is provided as a back up when sufficient heat is not available through solar energy which is the case during non sunny hours and cloudy days. When solar energy is in excess compared to the actual requirement, the pressure in the steam drum will increase and serve as a buffer storage system for hours when solar energy is not available. Control valves will operate to ensure that steam is available to the application at all times. The integration of solar system with the existing furnace oil heating system is shown in figure 4.

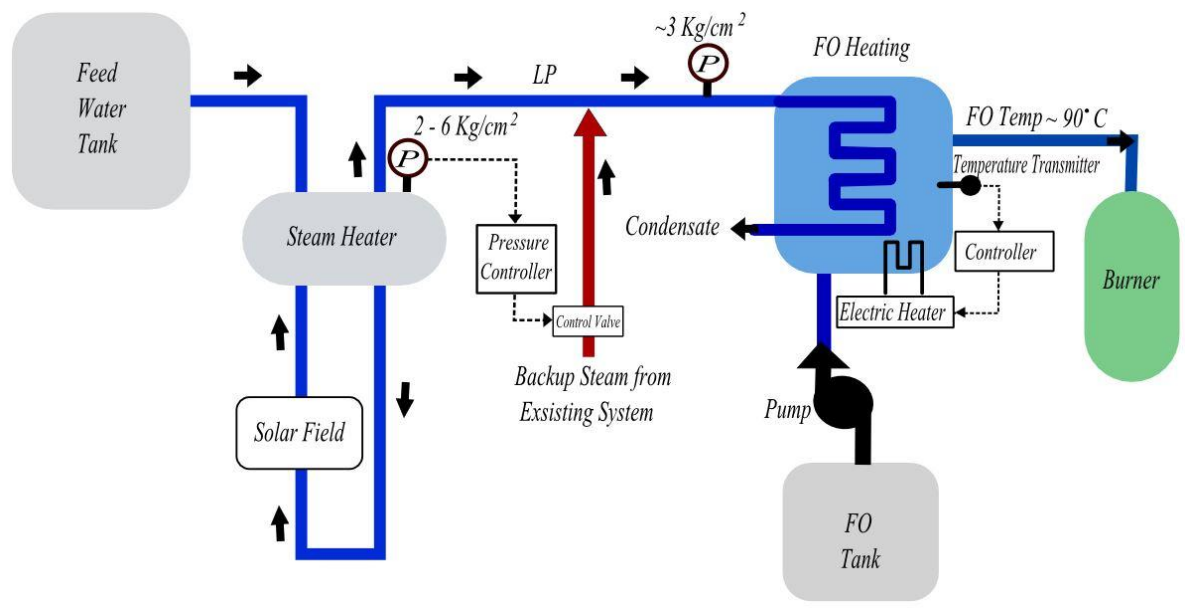

Figure 4: Integration of solar system with existing furnace oil heating system

Any appropriate concentrated solar thermal technology can be used in the solar field depending on site situation and space availability. Parabolic trough, Scheffler dish or paraboloid dish can be used to generate steam required for furnace oil heating.

\section{Seven Tank Dip Zinc Phosphating Heating Application by Solar Thermal Energy}

A paint shop of automobile industry uses a standard 7 tank dip zinc phosphating process before painting for good paint adhesion and corrosion resistance. The process flow is shown in the figure 5. The temperature requirement of each process depends on technology used in this pretreatment process and is typically in range of 60 to $80{ }^{\circ} \mathrm{C}$. The tanks are heated either by direct firing or by electrical immersion heaters, closed steam coils or thermal oil. 


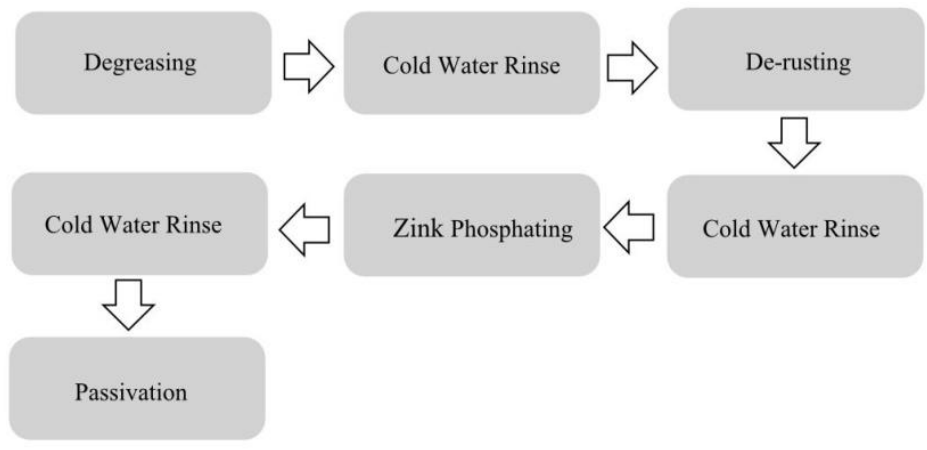

Figure 5: Process flow of standard 7 tank dip zinc phosphating process

\section{3 (a): Typical 7 Tank System}

All tanks are heated directly by using either electrical immersion heaters or by steam coils. Electrical heaters or hot water generators are used to heat the bath depending on the temperature requirement for the various bath sizes. The electrical immersion heaters are placed in the bath directly to the set temperature. Another heating system uses closed hot water heating coils where coils may be placed inside the tank, at the sides, leaving a clearance of a minimum of 1 foot for the sludge to settle down. The various fuels used to produce hot water are, liquid petroleum gas (LPG), high speed diesel (HSD), furnace oil (FO) or natural gas (NG). The typical temperature ranges of hot water at application for various processes without using pre-conditioner are as given in Table 2 [9].

Table 2: The typical temperature range of hot water application for various processes

\begin{tabular}{clccl}
\hline Tank & Function & Temperature $\mathbf{~}^{\mathbf{C}}$ & Dip time (Min) & Tank material \\
\hline 1. & Degreasing & $60-70$ & $1-2$ & Mild Steel \\
2. & Cold water Rinse & - & 1 & Mild Steel \\
3. & De-rusting & $60-70$ & $1-2$ & $\begin{array}{l}\text { Acid-resisting material, like } \\
\text { fiber glass or rubber lined. }\end{array}$ \\
& & & & $\begin{array}{l}\text { Acid-resisting material, like } \\
\text { fiber glass or rubber lined. }\end{array}$ \\
4. & Cold water rinse & - & 1 & Mild Steel \\
5. & Zinc Phosphate & $70-80$ & $1-2$ & Mild Steel \\
6. & Cold Water Rinse & - & 1 & Mild Steel \\
7. & Passivation & 70 & 1 &
\end{tabular}


3(b): Solar Integration with 7 tank system

Solar thermal energy can be used to generate hot water for low temperature applications. The existing system can be effectively integrated with the solar system to generate hot water. Existing system acts as a backup for steam generation when solar energy is not adequate. Figure 6 shows integration of solar system in a case with existing heating source for various processes.

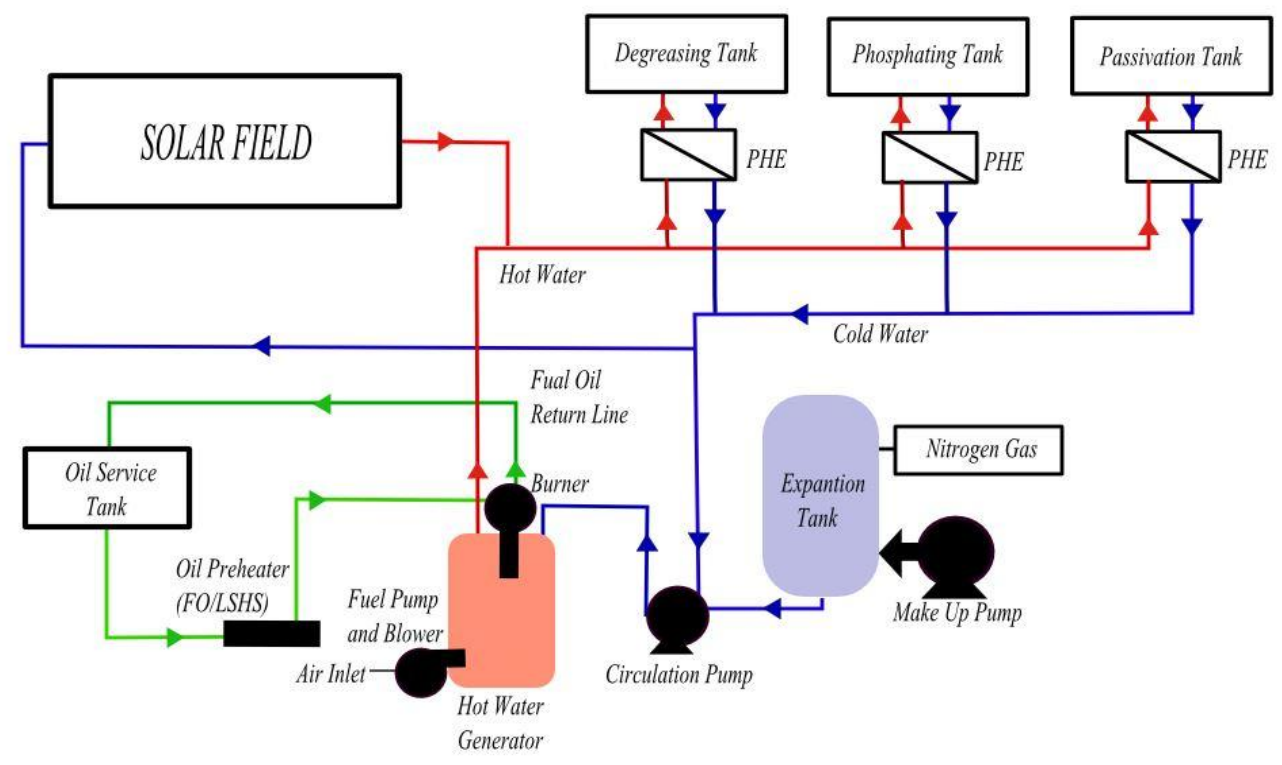

Figure 6: Integration of solar system with existing system for various heating processes

\section{A CASE STUDY OF CST SOLUTION FOR AUTOMOBILE COMPONENT WASHING PROCESS}

A case study of the CST based solar project for component washing application is discussed below. The automobile plant was commissioned in year 1945 and has been leading brand in India, which is the topselling tractor company in the world, with annual sales over 150,000, a presence in more than 40 countries and more than 1,000 dealers worldwide. The management is systematically shifting to renewable energy with stress on cost effective substitution.

Solar plant was installed and commissioned in year 2013 and has been regularly monitored for performance, costs and actual saving in electricity. The design objectives, philosophy and results are discussed in detail.

\section{Project Overview}

Project overview of installed and commissioned plant is given in Table 3. The automobile plant has four parallel stages of manufacturing Engine, Transmission, VTU (Vary Touch Unit) and Control Valve Components. In the key manufacturing process cycle, component cleaning is an important stage where components washing, degreasing and phosphating process is carried out in multiple tanks of varying temperatures. The temperatures of the tanks are maintained by electrical heaters and had substantial 
consumption of electricity for these processes which was monitored through a well established performance management system.

Table 3: Project overview of installed and commissioned plant

Client

Location, Latitude-Longitude

Application

Technology Used

Size and No. concentrators installed

Area of installation

Solar Project Cost

Design Output

Peak Thermal Output

Date of commissioning of the system

Earlier arrangement and reason for installation

Whether standalone system or integrated

Time of operation and tank capacity

Heat delivery on a clear sunny day

Operating temperature of fuel

Type and amount of fuel being saved in a year.
Indian Automobile Industry

Nagpur, India $21.1458^{\circ} \mathrm{N}, 79.0882^{\circ} \mathrm{E}$

Process heat for Automobile Component Washing

Compound Parabolic Concentrator,

442 sq.m, 130 CPC Concentrators

Concrete Rooftop, $750 \mathrm{~m}^{2}$

Rs. 88.44 Lakh

Hot Water $90{ }^{\circ} \mathrm{C}$

$950 \mathrm{~kW}$ Thermal per day

16.04 .2013

Electric Heaters, Electricity saving

Integrated

$4.5 \mathrm{~kL}$ tank capacity 10.00 am to $5.00 \mathrm{pm}$

638-937 kWh/day

$80-85{ }^{0} \mathrm{C}$

Electricity, 1,75,000 kWh/year

The key challenges for use of solar energy at this plant are,

1) To ensure maintenance of process temperature as per requirement and no process temperature variation beyond the set points was acceptable. The solar integration should take care of this requirement, considering variations in solar energy inputs during day and seasons.

2) Maximum utilization of solar energy by reducing daily electric consumption proportional to solar energy received on the day.

3) Integration project to be implemented without affecting production.

4) Use of roof top for solar energy collection and equipment installation as per Indian standards for building and structures which considers wind and earthquake loads. 


\section{Process Flow in the Automobile Plant}

The process flow in the automobile plant is as shown in the figure 7 with the process highlighted where Solar Hybridization has been put in place.

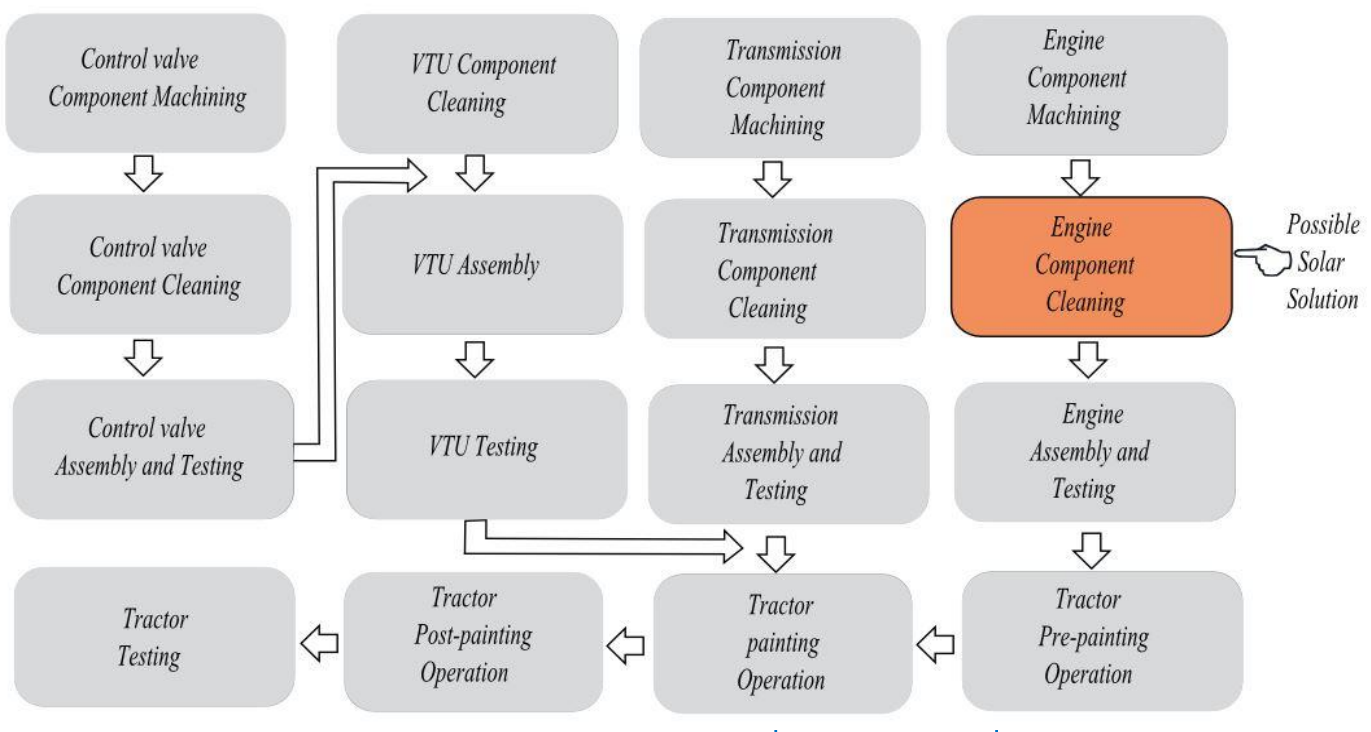

\section{Electric Heating system before solar integration}

In the existing system there are six numbers of engine component washing machines. Electric heaters are used to cater the heating requirement of the engine component washing machines. Figure 8 shows the heating arrangement before solar integration. The temperature requirement of the process is 60$70^{\circ} \mathrm{C}$.Temperature sensors sense and control the required temperature through control panel.

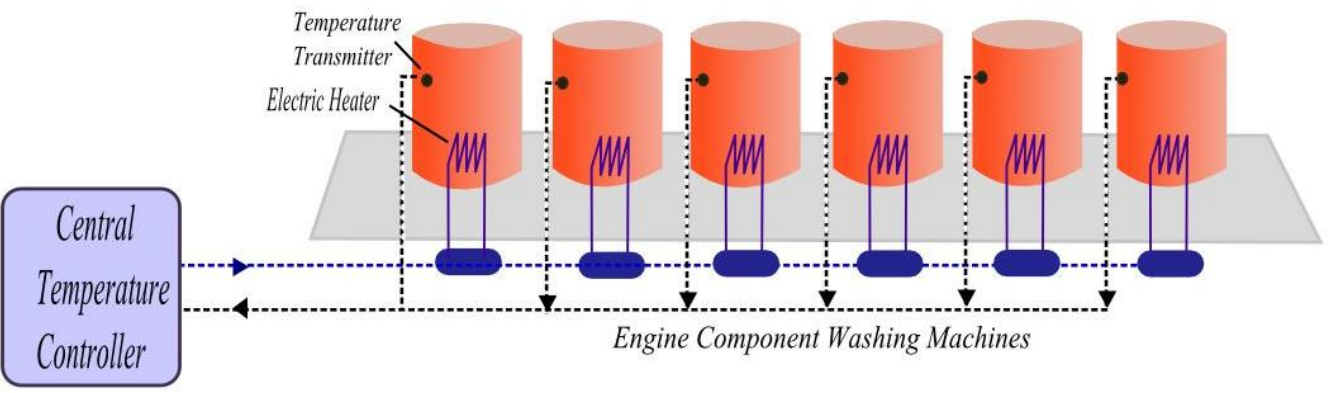

\section{Solar integration with existing system}

Considering the temperature requirement of the process, the roof structure and plant layout, a solar system using Compound Parabolic Concentrator (CPC) technology was installed. 


\section{4 (a): Compound Parabolic Concentrator}

The CPC collector consists of a selectively coated absorber tube that is enclosed in a concentric glass cover to reduce convection losses. The annulus between the tube and its cover is evacuated. The tube is placed at the focal plane of two reflectors shaped as parabolic troughs. The axes of the two parabolas are inclined at the acceptance angel which allows the reflected radiation to reach the receiver. The receiver carries the fluid to be heated [10]. The main components of the system in the compound parabolic concentrator are shown in the figure 9.

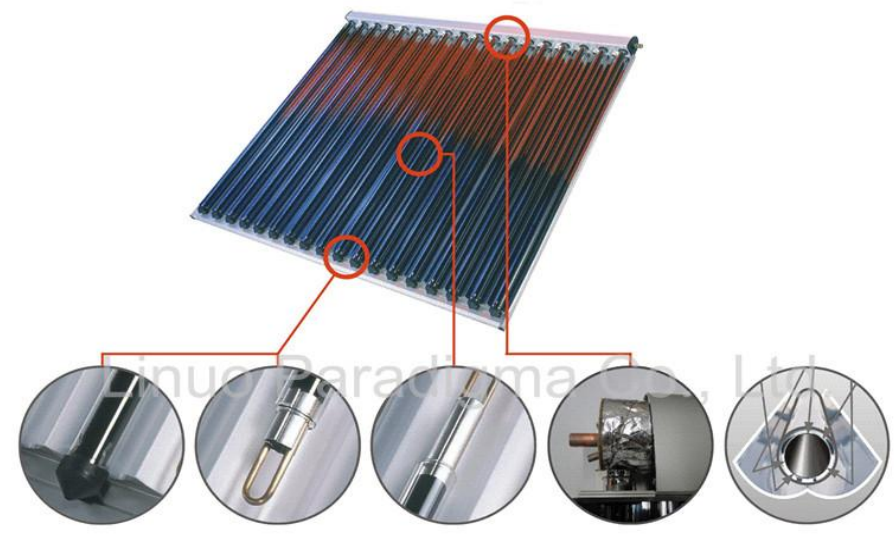

Figure 9: Compound parabolic concentrator details (Website:http://www.linuo-ritter-international.com)

The technology highlights ofcompound parabolic collector are,

$>$ Modular design and easy to install

$>$ Flat/ inclined roof as well as ground mounting is possible

$>$ Non-imaging collector. No tracking is required

$>$ Forced circulation system

$>$ Secondary reflector ensures maximum solar radiation capture across seasonal variation

$>$ The compound parabolic shape of CPC collector concentrates diffused and non-incidental radiation along with beam radiation

$>$ Selective aluminum nitride coated evacuated absorber captures maximum heat energy and reduces heat losses to a minimum

\section{4 (b): Solar System Design}

Solar non-imaging collectors, CPC, are used to generate high temperature water at $85{ }^{0} \mathrm{C}$. The solar generation plant consists of solar collectors, circulation pump, water storage tank, valves and control etc. In the system, initially the temperature of water is increased by several passes through storage tank. The collector starts collecting solar energy within a short while after sun rise and temperature of water in collectors rises. This temperature is sensed by temperature sensor which puts on the circulation pump and forces the primary circuit water through the solar collectors. The heat gained by solar collectors is transferred to the storage tank. When water in storage tank reaches desired temperature of $85{ }^{0} \mathrm{C}$, it is 
supplied to the process. The electric heaters are provided on the component washing tanks which switches on when the desired temperature cannot be reached through solar system due to lower radiation level or during non-sunny hours/days. Water from storage tank is circulated through the heat exchangers which indirectly maintain required temperature at process tanks and the water after giving out its heat is brought back to the storage tank and cycle continues. This solar process heating system is a unique solution that generates process heating water as high as $90{ }^{\circ} \mathrm{C}$. It also seamlessly integrates with the existing system without compromising on its reliability, while reducing electricity consumption. The system schematic is shown ir
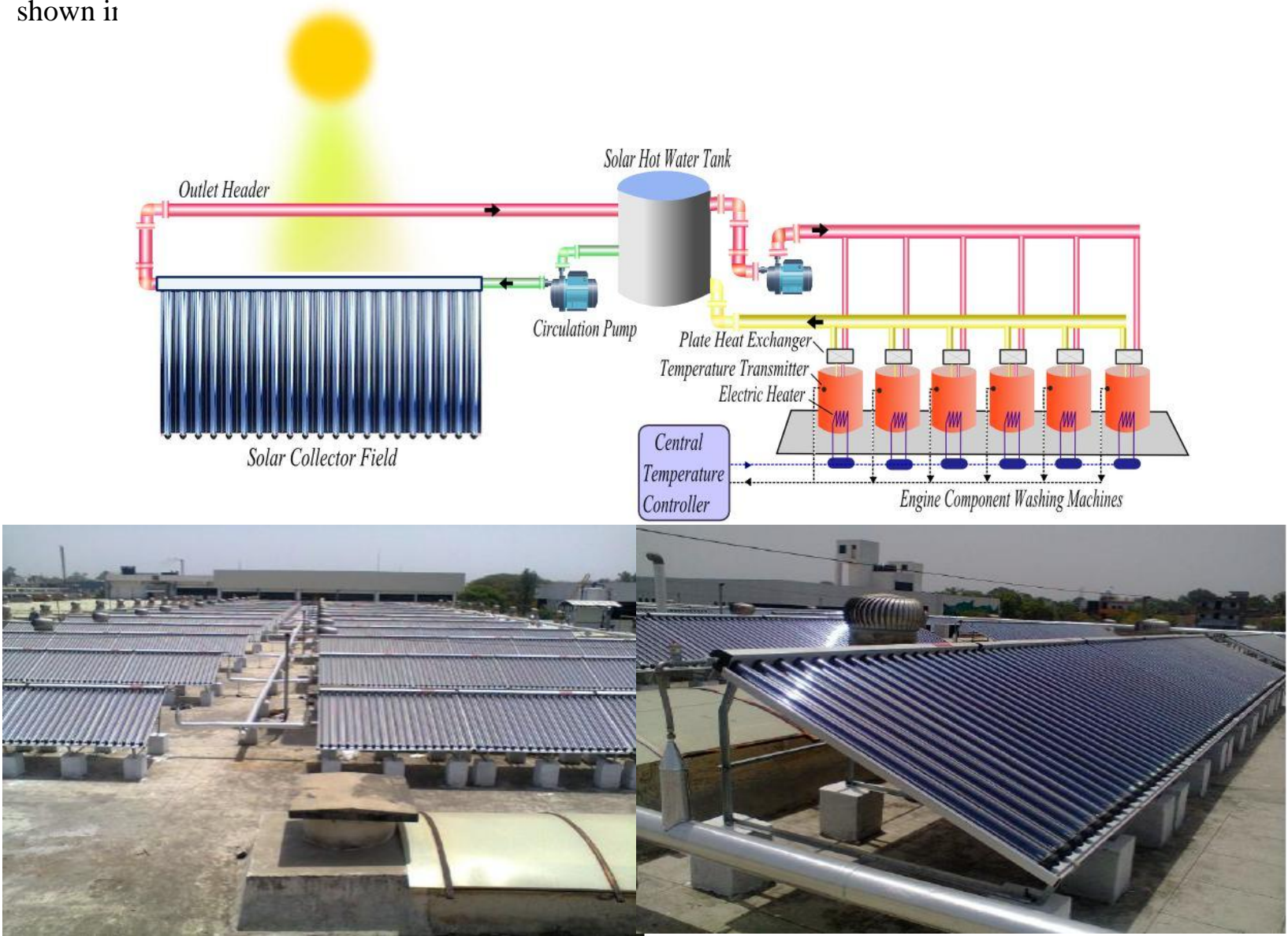

Figure 11: Actual photograph of CPC based solar installation at an automobile industry

\section{System Performance Results}

System output was monitored daily for one year, in 2014 and data was analyzed to know the heat output in $\mathrm{kW}_{\mathrm{Th}} /$ day. Remote monitoring system for data monitoring and logging was installed for measuring and recording the weather parameters like solar radiation, ambient temperature and wind speed as well as the system parameters like, solar field inlet water temperature, outlet water temperature, storage tank temperature process tank temperatures and fluid flow rate were recorded at the interval of one minute. All the instruments and sensors used for data measurement were of precision type. The data was analyzed and heat output was calculated on daily basis. The output for the months of June, July and August was negligible due to monsoon clouds. Total units of electricity saved in the year 2014 were 1,74,910 kWh, 
which is equivalent to $164 \mathrm{MT}$ of $\mathrm{CO}_{2}$ emission. Month wise average daily heat output corresponding to the daily solar radiation incident is shown in figure 11. Note that the heat output for the months of June, July and August (shown by *) has not been considered as it was negligible due to rainy season.

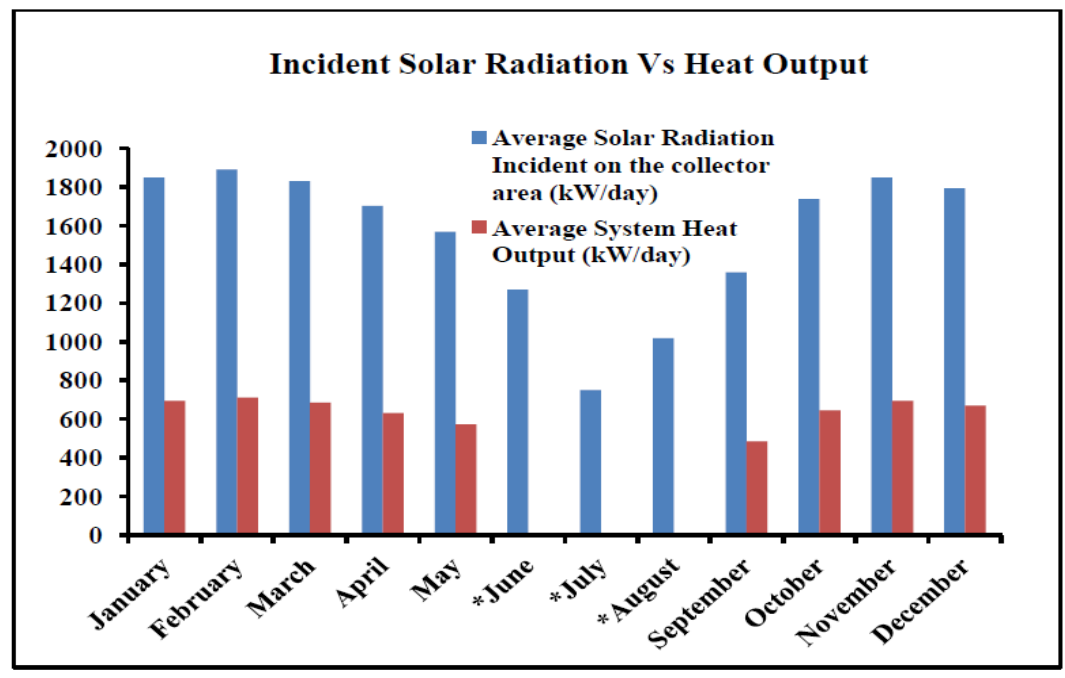

Figure 11: Month wise average daily solar radiation Vs heat output

\section{Economic Analysis}

Saving in electricity/year based on performance data $\quad: 1,74,910 \mathrm{kWh}$

The cost of electricity at the plant $\quad:$ Rs $8.2 / \mathrm{kWh}$

Savings accrued

: Rs $14,34,262 /$ year

Simple payback

: 6 Years

Considering the benefits offered by Government of India for renewable energy by way of subsidy and cash benefit, the payback is $<5$ years. The system is running since installation and monitored through remote monitoring system connected through internet to PLC system at the plant. Except occasional cleaning of dust from collectors using water, and routine mechanical maintenance of pumps etc, there are no major recurring expenses since installation. The plant has withstood hail storm as well as hurricane without any damage.

\section{CONCLUSION}

The heat energy requirement of Automobile Industry can be partially met by solar hybridization with existing system. With the area available on the roof top and need for medium temperature requirement, Automobile Industry is most suitable for substitution of conventional fuels with solar energy. Solar thermal energy based systems can be seamlessly integrated with existing heat source for a few processes in automobile industry which are highlighted in this paper. The case study data validates the possibility of integration of solar system with the existing heat source for engine component washing process. The CPC collectors installed at the plant has demonstrated generation of process heating water as high as 90 ${ }^{0} \mathrm{C}$. The design seamlessly integrates with the existing electric system without compromising on its reliability while reducing electricity consumption proportional to incident solar energy. The annual saving 
of 1,75,000 units of electricity and in turn 164 Metric Tons of $\mathrm{CO}_{2}$ emission was achieved using $442 \mathrm{~m}^{2}$ of CPC collector area with a payback period of 4-5 years.

\section{References}

[1] European Solar thermal Industry Federation, Key Issues for Renewable Heat in Europe (K4RES-H), Solar Industrial Process Heat-WP3, Task 3.5

[2] www.irena.org: IEA-ETSAP and IRENA ${ }^{\circledR}$ Technology Brief E21-January 2015

[3] www.uneptie.org/energy, Technical study report on Solar Heat for Industrial Processes (SHIP), State of the art in the Mediterranean region

[4] www.solar.uni-kassel.de, Solar heat for industrial processes-Technology and potential

[5] www.siamindia.com, Society of Indian Automobile Manufacturers (SIAM)

[6] www.cshindia.in, Ministry of New and Renewable Energy, Concentrated Solar Heat

[7] http://www.altenergy.com/Default.htm Alternate Energy Systems, Inc.

[8] https://beeindia.gov.in/sites/default/files/2Ch1.pdf Fuels and Combustion

[9] www.thinchemie.comDip zinc phosphating-Thin Chemie Formulations

[10] http://www.linuo-ritter-international.com 